Boise State University

ScholarWorks

Geosciences Faculty Publications and

Presentations

Department of Geosciences

5-26-2006

\title{
Reflectivity Modeling of a Ground-Penetrating-Radar Profile of a Saturated Fluvial Formation
}

\author{
William P. Clement \\ Boise State University \\ Warren Barrash \\ Boise State University \\ Michael D. Knoll \\ Boise State University
}

This document was originally published by Society of Exploration Geophysicists in Geophysics. Copyright restrictions may apply. DOI: 10.1190/1.2194528 


\title{
Reflectivity modeling of a ground-penetrating-radar profile of a saturated fluvial formation
}

\author{
William P. Clement ${ }^{1}$, Warren Barrash ${ }^{1}$, and Michael D. Knoll ${ }^{1}$
}

\begin{abstract}
Major horizons in radar reflection profiles may correlate with contacts between stratigraphic units or with structural breaks such as fault surfaces. Minor reflections may be caused by clutter or, in some cases, may indicate material properties or structure within stratigraphic units. In this study, we examine the physical basis for major and minor reflections observed in a shallow, unconfined, fluvial aquifer near Boise, Idaho, U. S. A. We compare a 2D profile from a surface ground-penetrating-radar reflection transect with the 1D modeled reflection profiles at three wells adjacent to the surface-reflection profile. The 1D models are based on dielectric constant and electrical conductivity values from borehole logs and vertical radar profile data. Reflections at the water table/capillary fringe, at the base of a sand-filled channel, and at the base of two sand-rich lenses in a cobble-dominated unit are recognizable in the surfacereflection profile and in all $1 \mathrm{D}$ reflectivity models. Less prominent reflections in stratigraphic units occur in both the surface-profile model and the reflectivity model. Although such minor reflections are not correlated easily, general similarities in their presence and location indicate that sometimes the reflections may be useful for recognizing internal facies structure or character.
\end{abstract}

\section{INTRODUCTION}

Surface-radar reflection profiling is used widely to image shallow subsurface stratigraphy and structure on the basis of the presence of significant reflectors (Beres and Haeni, 1991; Huggenberger, 1993; Beres et al., 1999; Tronicke et al., 2002). Such reflectors occur at contrasts in electromagnetic properties, but questions remain about the nature of the distribution of physical properties within the subsurface. Without precise velocity and depth informa- tion, we cannot determine the thickness of the reflecting packages. Also, we do not fully understand the nature of the contrast, especially at the water table. Does the reflection indicate an abrupt boundary, or is the boundary gradational, like a capillary fringe? Furthermore, the data contain many events and less prominent reflection patterns between major reflectors. Are those events noise, systematic indicators of different facies, or perhaps the result of out-of-plane scattering?

Several studies have combined physical-property measurements with ground-penetrating radar (GPR) to help geoscientists understand the internal structure of the subsurface. Kohler et al. (2003) used GPR to understand the structure of the snowpack or firn of the Svalbard glacier in Norway. They measured the electromagnetic (EM) properties every $2.5 \mathrm{~mm}$ of a firn core taken near the GPR line, using a 4-cm wide electrode. Using a convolutional model, they developed a reflectivity series to compare with their GPR data. Hempel et al. (2000) matched GPR reflections in the Greenland ice sheet to fine-scale (1-mm) measurements of the electrical conductivity from an ice core near the GPR profile. For their comparison, they used common-depth-point (CDP) profiles to determine the velocity layering in the glacier.

In a subsurface reservoir-analog experiment, Szerbiak et al. (2001) measured dielectric permittivity, electrical conductivity, and fluid permeability from outcrops and cores of the Ferron Sandstone in east-central Utah. They developed models that used finitedifference simulation to generate synthetic, zero-offset traces. Then they compared those synthetic traces with their GPR data. Arcone et al. (1998) computed dielectric permittivity from reflection-event time delays, and they fitted curves to diffractions and refractions to get interval velocities of events in GPR data. They used the velocity information to map the thickness of the permafrost and the depth to the water table and to bedrock. They used boreholes at the site to check their depth estimates.

Van Dam and Schlager (2002) used time-domain reflectivity (TDR) to measure the velocity profile at the face of a cliff, and they used that velocity to compare with surface GPR acquired near the cliff edge. They converted the TDR-derived velocities to dielectric

Manuscript received by the Editor January 14, 2004; revised manuscript received July 13, 2005; published online May 24, 2006.

${ }^{1}$ Center for Geophysical Investigation of the Shallow Subsurface, Boise State University, 1910 University Drive, Boise, Idaho 83725. E-mail: billc@cgiss.boisestat.edu; wb@cgiss.boisestate.edu; mknoll@cgiss.boisestate.edu. (C) 2006 Society of Exploration Geophysicists. All rights reserved. 
permittivity values, which they then used in a model to generate synthetic traces to compare with GPR profiles acquired along the top of the basalt. To better understand radar reflections in the vadose zone, van Dam et al. (2003) developed synthetic GPR traces using TDR probes and grain-size analysis of thin sections. However, the scale of those measurements was too small to compare with the actual surface GPR reflection profiles collected at the site.

The studies mentioned above used laboratory techniques or indirect methods to measure the EM properties of the materials in the subsurface sampled by GPR. We hypothesize that in situ measurements of the EM physical properties in the subsurface can be used to accurately model the GPR-reflection response of that material. If the physical factors affecting the generation of reflections were better understood and a method existed to calibrate reflection profiles independently, more quantitative information may be available in surface-reflection profiles, or the accuracy of reflection-profile images may improve, or both.

In our study, we developed synthetic traces by using geophysical logs and vertical radar profiles (VRP) from wells at the site, and we related those traces to the reflection character observed in a surface profile conducted between the wells. Thus, we linked the in situ, measured distribution of changes in physical properties to reflections recorded in a surface GPR profile. Our method used borehole logs and VRPs to sample a larger volume of the subsurface than laboratory tests on selected cores can sample. Because our goal is to match surface reflections to synthetic traces derived from wells, we acquired a 20 -m-long surface profile that extended slightly beyond the two outer wells. We also acquired the surface data with $200-\mathrm{MHz}$ antennas to better match the frequency of the $250-\mathrm{MHz}$ borehole antennas.

We used the borehole data to estimate the input parameters needed to forward model synthetic radar reflections in one dimen-

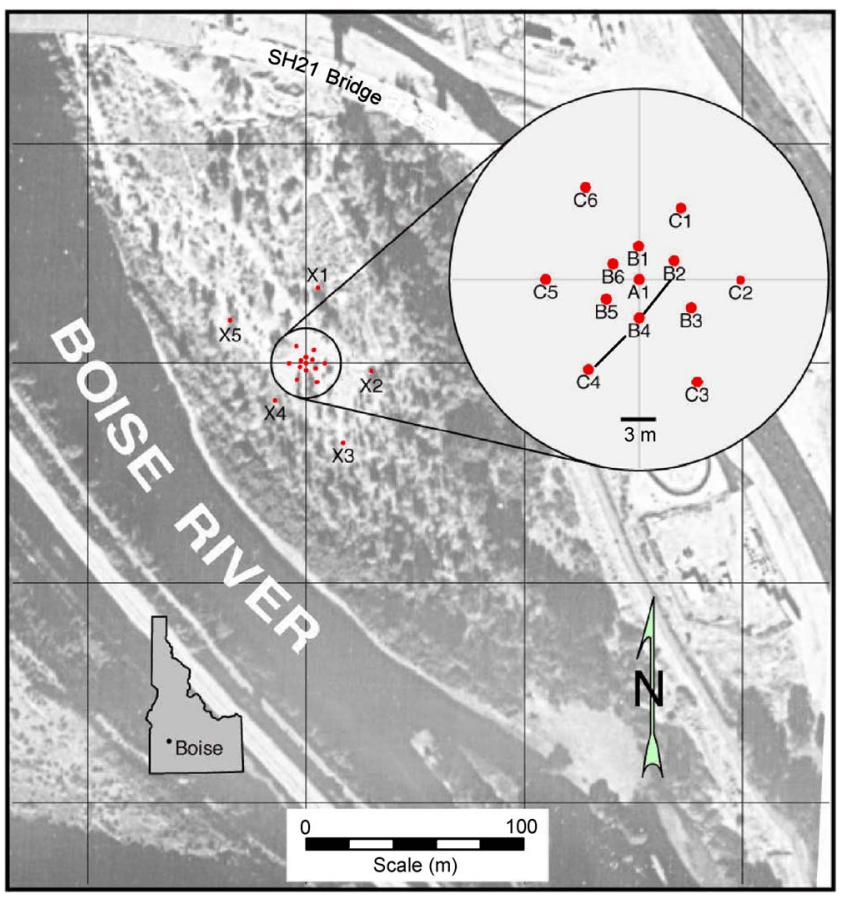

Figure 1. Location of the Boise Hydrogeophysical Research Site. The inset shows the geometry of the well field at the BHRS. The reflection survey profile is between wells B2, B4, and C4. sion. We compared those synthetic traces with observed reflection profiles at locations adjacent to the boreholes. The VRPs and core data provide partial calibration with respect to changes in velocity or stratigraphy, depending on the nature and dimension of the geologic materials and their properties.

The data for this study came from the Boise Hydrogeophysical Research Site (BHRS) (Barrash and Knoll, 1998). At that site, the distribution of properties and structures in a coarse, high-energy fluvial deposit provides a variety of radar-reflection-imaging targets with subsurface control from cores, wireline logs, and VRPs at wells.

\section{HYDROGEOLOGIC SETTING}

Our study was located at the BHRS, a research wellfield developed within a gravel bar adjacent to the Boise River (Figure 1). The gravel bar contains unconsolidated coarse (cobble and sand) sediments deposited in a braided-stream environment (Barrash et al., 1999; Clement et al., 1999). Data from porosity logs and core (Barrash and Clemo, 2002; Barrash and Reboulet, 2004) indicate that the coarse fluvial deposits are $\sim 18 \mathrm{~m}$ thick and can be subdivided into five stratigraphic units (Figure 2). The water table is shallow, and its depth generally ranges seasonally from $\sim 1 \mathrm{~m}$ to $3 \mathrm{~m}$ below the land surface. We estimate that the capillary fringe above the water table is 0.05 to $0.15 \mathrm{~m}$ thick (Lohman, 1972; Dullien, 1979; Holtz and Kovacs, 1981). This thickness estimate is based on the grain-size distribution and the porosity of the sand in Unit 5 and on the sand-to-fine-gravel material filling the interstices between framework cobbles in Unit 4 (Reboulet, 2003; Hughes, 2005). We expect that the water saturation rapidly decreases above the capillary fringe for these sediments in Boise's desert environment (e.g., Bear, 1972).

Along our transect, which crosses the central area of the BHRS (Figure 1), we defined a stratigraphy that is based on the porosity logs and is supported by grain-size analysis (Figure 2). A sandfilled channel (Unit 5) occurs at the top of the saturated section. The channel thickens toward the Boise River to the southwest and pinches out between wells B4 and B2 at the center of the well field (Figures 1 and 2). Units 1 and 3 consist of low-porosity (an average porosity of $0.17-0.18$ ) cobble-dominated units with no relatively sand-rich lenses. Cobble-size framework grains also dominate Units 2 and 4, but these units have higher porosity (an average porosity of $0.23-0.24)$, more variable porosity, and some sand-rich lenses. In addition, strong porosity contrasts occur in Unit 4, at the boundaries of local lenses (e.g., at $5.5 \mathrm{~m}$ in well B2 and at $5 \mathrm{~m}$ in well $\mathrm{C} 4$ ) that have varying proportions of framework cobbles and matrix sand (Reboulet and Barrash, 2003). Previously recorded strong reflections in surface radar (Peretti et al., 1999) and borehole (Clement et al., 2001) radar and in borehole seismic profiles (Liberty et al., 1999) have been interpreted to occur at some unit boundaries and locally within some units, especially Unit 4.

\section{GPR METHODS}

We used a pulseEkko 100 with $200-\mathrm{MHz}$ antennas, a $400-\mathrm{V}$ transmitter, and an 0.8-ns sample interval. The antenna separation was $0.5 \mathrm{~m}$, and the data were collected at $0.1-\mathrm{m}$ intervals. The transect was $\sim 20 \mathrm{~m}$ long (Figure 3 ). Each trace represents a stack of 64 traces to enhance the signal-to-noise ratio. Processing of the reflection data consisted of (1) removing the low-frequency bias, 
(2) filtering the data between 20 and $200 \mathrm{MHz}$ to remove noise, (3) migrating the data using a three-layer simplification of the velocities from the 1D velocity analysis discussed in the next section, (4) enhancing later-arriving reflections with a 25-ns automatic gain control (AGC) window, and (5) normalizing each trace by its maximum amplitude.

\section{REFLECTION SURVEY}

We interpret strong, coherent reflections in the surface GPR reflection data (Figure 3 ) to represent bounding surfaces between different sediment packages (i.e., stratigraphic units or lenses within units). Between those bounding surfaces, weaker, discontinuous reflections are visible and likely indicate internal bedding structures in some locations. We estimate that the depth at which coherent reflections disappear is $\sim 6 \mathrm{~m}(\sim 130 \mathrm{~ns})$.

In detail, the strong arrival at $\sim 12 \mathrm{~ns}$ two-way traveltime (TWTT) across the profile is the directly coupled airwave (A in Figures $3 \mathrm{a}$ and $\mathrm{3b}$ ). Below the airwave, weaker, less continuous reflections occur between 25 and 40 ns. A reflection or set of com-
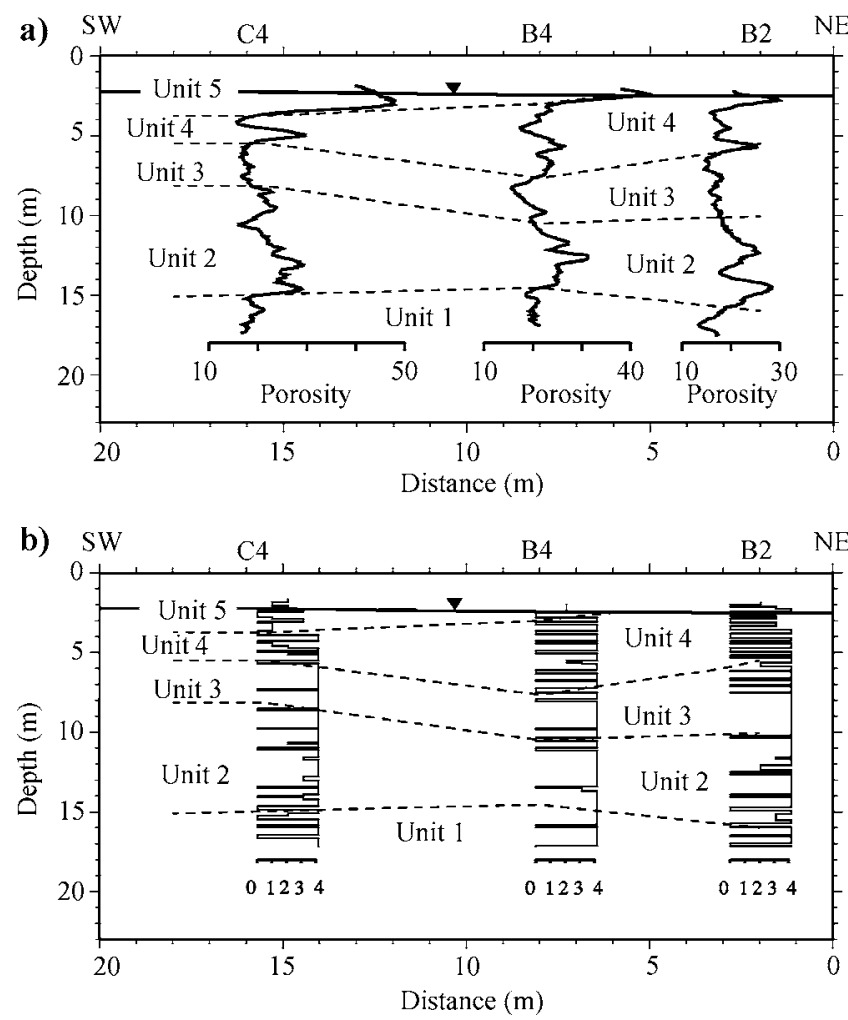

Figure 2. (a) Neutron-derived porosity logs and (b) grain-size distribution from the BHRS. The porosity character and grain-size analysis of the cores define the units. Unit 5 is a sand-filled channel. Units 1 and 3 are cobble-dominated units with similar low porosities and no relatively sand-rich lenses. Units 2 and 4 are cobble-dominated units with higher and more variable porosities than units 1 and 3 have, and with some relatively sand-rich lenses. The porosity scale in (a) is in percent (dimensionless). The scale in (b) is as follows: 0 indicates no recovery; $1=$ sand; $2=$ cobbles floating in sand; $3=$ bimodal distribution of cobbles and sands; and $4=$ cobble framework with sand matrix. The GPR energy in Figures 3 and 7 penetrates to a depth of about $6 \mathrm{~m}$. The solid line at about $2.5 \mathrm{~m}$ marks the depth of the water table at the time of the GPR acquisition, not at the time of the neutron log acquisition. plex reflections (B) coinciding with the water table and/or capillary fringe occurs at $\sim 25 \mathrm{~ns}$ and is most coherent between 12 and $19.5 \mathrm{~m}$ on the profile's distance scale. A strong reflection $(\mathrm{G})$ is the basal bounding surface of the sand-filled channel (Unit 5 in Figures 2 and $3 \mathrm{c}$ ), which can be traced from $\sim 95 \mathrm{~ns}$ at $19.5 \mathrm{~m}$ in the southwest to $\sim 70 \mathrm{~ns}$ at $7 \mathrm{~m}$ near B4. The reflection character below this bounding surface contains complicated events, thereby indicating a complex reflecting interface. These events may signify some small migration artifacts or out-of-plane reflections. The sediments at the BHRS contain some large cobbles, so out-of-plane reflections and a complicated reflection character are expected.
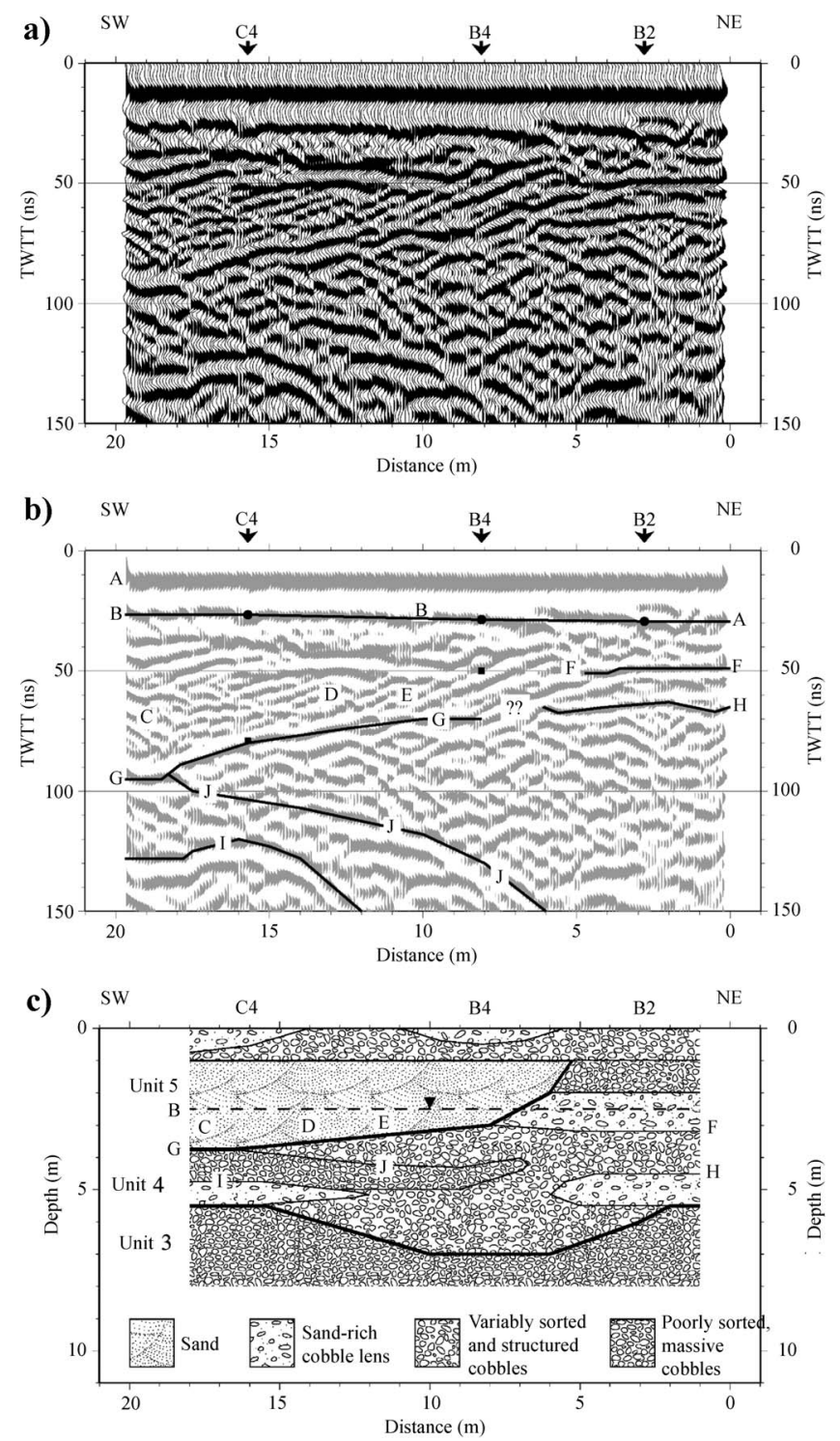

Figure 3. (a) A migrated surface-reflection profile using $200-\mathrm{MHz}$ antennae. Letters A through $\mathrm{H}$ are the events discussed in the text. The wells are labeled along the top. (b) The same plot as 3a, but annotated here to show more clearly the events discussed in the text. Circles mark the expected time of the water table measured in the wells. Squares mark the expected time for the contact between Units 5 and 4 from Figure 2. TWTT refers to two-way traveltime. (c) Geologic interpretation coinciding with the GPR reflection profile based on the well logs and recovered cores. 
Another strong reflection $(\mathrm{H})$ crosses the section from $\sim 60 \mathrm{~ns}$ at $0 \mathrm{~m}$ in the northeast, to $\sim 60 \mathrm{~ns}$ at $6.5 \mathrm{~m}$ in the lateral position. This reflection coincides with the top of the higher-porosity lens in Unit 4 at 3.5-m depth in well B2 (Figures 2 and 3c). It appears to be continuous southwestward to $\mathrm{B} 4$, where it ends or is truncated by the sand-filled channel. Reflection $\mathrm{F}$, at $\sim 50 \mathrm{~ns}$ from 0 to $5 \mathrm{~m}$, is close to the water table. This reflection may be from the water table, although the water table occurs at about $30 \mathrm{~ns}$ at well B2. Alternatively, reflection $\mathrm{F}$ may return from the lower surface of the relatively sand-rich lens between $\sim 2.5$-and 3.5 -m depth in well B2. A reflection $(\mathrm{J})$ branches from reflection $\mathrm{G}$ at about $95 \mathrm{~ns}$ and $18 \mathrm{~m}$ and continues to $150 \mathrm{~ns}$ near $6 \mathrm{~m}$. This reflection probably returns from the top of a coarser lens in Unit 4. Finally, a reflection (I) extends from $125 \mathrm{~ns}$ at the southwest end of the profile to $150 \mathrm{~ns}$ at $12 \mathrm{~m}$. The boundary between two lenses at about 5-m depth is the probable source for this reflection.

Sets of parallel dipping reflections (Figure 3 ) are interpreted to be cross-bedding (Unit 5) in the sand-filled channel [similar events are seen in Beres and Haeni (1991) and in Huggenberger (1993)]. They occur to the southwest of $\mathrm{C} 4$ (reflection $\mathrm{C}$ between 30 and 50 $\mathrm{ns}$ ) and below and to the southwest of B4 (reflection E at $\sim 50 \mathrm{~ns}$ ). Reflection $\mathrm{D}$ occurs between cross-bedding reflections at $\mathrm{C}$ and $\mathrm{E}$ and may be a related feature with a different orientation. Other less continuous reflections occur below the sand-filled channel.

\section{REFLECTIVITY ANALYSIS}

We used vertical radar profiles (VRPs) and borehole logs from wells to derive profiles of dielectric permittivity $\varepsilon$ and conductivity $\sigma$. We used these parameters to compute the complex impedance $Z$ of a layer

$$
Z(\text { ohms })=\sqrt{\frac{\mu}{\varepsilon}}\left(1+\frac{\sigma}{i \omega \varepsilon}\right)^{-1 / 2},
$$

where $\mu$ is the magnetic permeability (in $\mathrm{H} / \mathrm{m}$ ), $\varepsilon$ is the dielectric permittivity (in $\mathrm{F} / \mathrm{m}$ ), $\sigma$ is the electrical conductivity (in $\mathrm{S} / \mathrm{m}$ ), and $i$ is $\sqrt{-1}$. Then, the reflectivity of a particular interface is

$$
\mathrm{R}=\frac{\mathrm{Z}_{2}-\mathrm{Z}_{1}}{\mathrm{Z}_{2}+\mathrm{Z}_{1}}
$$

where subscript 1 refers to the overlying layer and subscript 2 refers to the lower of two layers. Reflections are most sensitive to changes in dielectric permittivity because of the small range in electrical conductivity and the assumed uniform value for magnetic permeability for these sediments. Often, the dielectric permittivity is represented by the real part of the relative permittivity or the dielectric constant

$$
\varepsilon_{\mathrm{r}}=\frac{\varepsilon}{\varepsilon_{0}}
$$

where $\varepsilon_{0}$ is the dielectric permittivity in a vacuum $(8.854$ $\left.\times 10^{-12} \mathrm{~F} / \mathrm{m}\right)$. The relative magnetic permeability is

$$
\mu_{\mathrm{r}}=\frac{\mu}{\mu_{0}}
$$

where $\mu_{0}$ is the magnetic permittivity in a vacuum $(1.257$ $\left.\times 10^{-6} \mathrm{H} / \mathrm{m}\right)$. a) Time (ns)

b) Velocity $(\mathrm{m} / \mathrm{ns})$
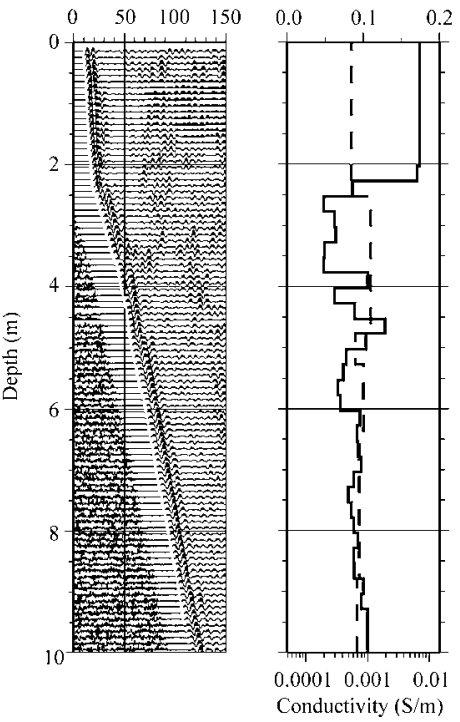

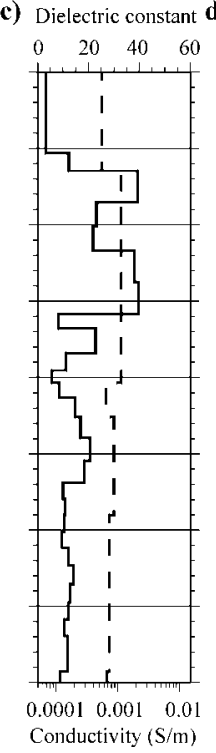

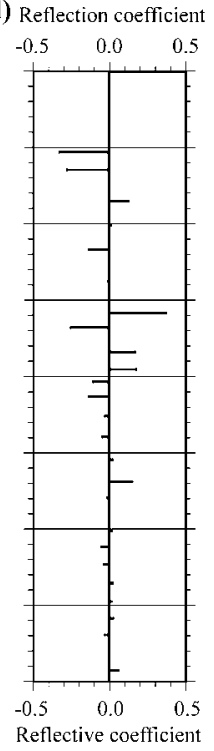

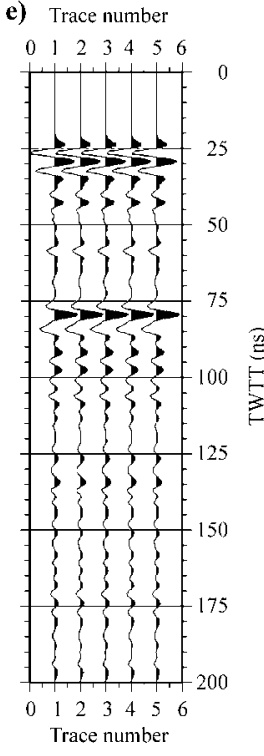

Figure 4. (a)VRP; (b) velocity (solid line) and conductivity (dashed line) models; (c) dielectric constant (solid line) and conductivity (dashed line) models; (d) reflection coefficients; and (e) synthetic radar traces for well C4. In plots (a) and (b), the vertical axis is depth in meters; in (c) through (e), the vertical axis is two-way traveltime in nanoseconds.

\section{VRP surveys}

Vertical radar profiles (VRPs), like vertical seismic profiles (VSPs), are used to measure one-way traveltime. In this method, a source is placed at the surface and a receiver is placed downhole. We used the Mala RAMAC system with 250$\mathrm{MHz}$ antennas. We placed the transmitter antenna on the surface with the antenna horizontally polarized in a radial direction. The center point of the antenna was $1.34 \mathrm{~m}$ from the well. The receiver antenna was vertically polarized and lowered in the borehole in 0.1-m intervals.

In general, the first-arrival events define three linear trends (Figures 4-6). In the C4 VRP (Figure 4a), the first trend extends to $\sim 2.25 \mathrm{~m}$ below the surface. This trend has a fast apparent velocity of $\sim 0.17 \mathrm{~m} / \mathrm{ns}$ and probably is a refraction of the airwave along the surface (Tronicke and Knoll, 2005). Below $2.25 \mathrm{~m}$, the velocity is nearly $0.07-\mathrm{m} / \mathrm{ns}$ to $\sim 3.8-\mathrm{m}$ depth, where the velocity increases to 
$\sim 0.09 \mathrm{~m} / \mathrm{ns}$. To the first order, these velocities define a three-layer model for the uppermost $10 \mathrm{~m}$.

To provide a more detailed velocity profile, we used VRP firstarrival traveltimes to compute a $1 \mathrm{D}$ velocity profile at wells $\mathrm{C} 4$, B4, and B2 (Figures 4b, 5b, and 6b). We inverted the traveltimes for layer velocities using a weighted, smoothed, least-squares inversion method (Lizarralde and Swift, 1999). The inversion solves for velocities in constant, 0.25 -m-thick layers. Below $\sim 1.7 \mathrm{~m}$, the velocities from the multilayered inversion show a large-scale velocity structure similar to the three-layer model calculated from linear fitting of the traveltimes (Figures $4 b, 5 b$, and $6 b$ ). In the uppermost $1.7 \mathrm{~m}$, the model underestimates the measured velocity, probably because of the straight-ray assumption in the forward model. The inversion assumes that the energy propagates along straight raypaths between the transmitter and the receiver. In the near surface, the first arrivals mostly propagate along strongly curved raypaths, so that straight lines poorly approximate the true travel path. Below the water table ( $2.25 \mathrm{~m}$ in Figure $4 \mathrm{~b})$, the inverted velocities indicate a low-velocity zone to 4-m depth, and then they alternate between higher and lower values. Below $\sim 6 \mathrm{~m}$, the velocity varies less and averages $\sim 0.09 \mathrm{~m} / \mathrm{ns}$.

\section{Input to $1 \mathrm{D}$ reflectivity models}

Input to $1 \mathrm{D}$ reflectivity models at wells $\mathrm{C} 4$, B4, and B2 consisted of values for dielectric constant, electrical conductivity, and relative magnetic permeability assigned to 250-m-thick layers, similar to the layering in the VRP inversion (Figures 4-6). The neutron (porosity) logging and capacitive resistivity tools do not collect useful data above the water table, so we estimated the physical properties in the upper $\sim 2.5 \mathrm{~m}$. We estimated a dielectric constant of $3.0(0.17 \mathrm{~m} / \mathrm{ns})$ and a conductivity of $0.55 \mathrm{mS} / \mathrm{m}$ for the extremely dry vadose zone. This low estimate of the dielectric constant is based on the desert environment, the low moisture content in the coarse unconsolidated sediments, and the quartz-rich sediment clasts derived from the largely granitic terrain of the Boise River drainage above the BHRS (Mitchell and Bennett, 1979; Barrash et al., 1997).

Below the water table, measurements of physical properties provided the values for the model. For the input reflectivity model, we derived the dielectric constants from the multilayered VRP inverted velocity profiles using $\sqrt{k}=c / v$, where $c$ is $0.3 \mathrm{~m} / \mathrm{ns}$, the velocity of EM waves in air. The dielectric constant values range between 3 and 51. We derived the con- ductivity values from capacitive resistivity well logs taken at the site (Mwenifumbo and Knoll, 2004). The conductivity values are low and have a narrow range $(0.55-1.13 \mathrm{mS} / \mathrm{m})$ in coarse, clean, quartzo-feldspathic sediments, with a low concentration of total dissolved solids in the aquifer water (Barrash et al., 1997; Hausrath et al., 2002). We gave the relative magnetic permeability a constant value of 1 for the entire model because most of the sediments at the site consist primarily of nonmagnetic granitic material, with relatively few basalt cobbles.

The profiles of reflectivity coefficients show strong, negative reflection coefficients near the water table (Figures 4d, 5d, and 6d)
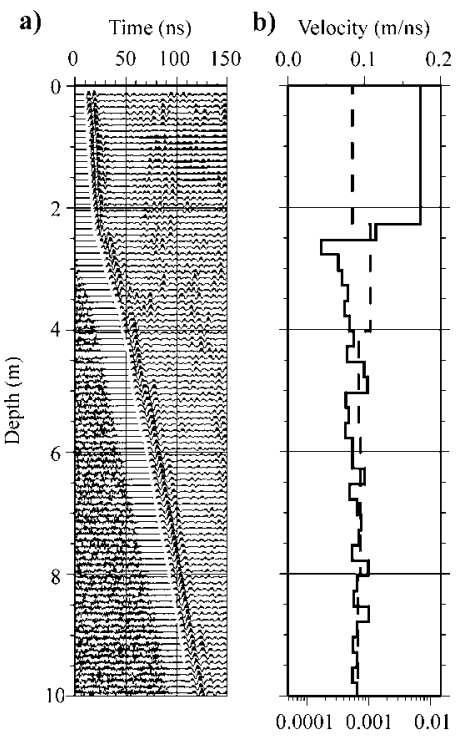

$0.00010 .001 \quad 0.0$ Conductivity $(\mathrm{S} / \mathrm{m})$
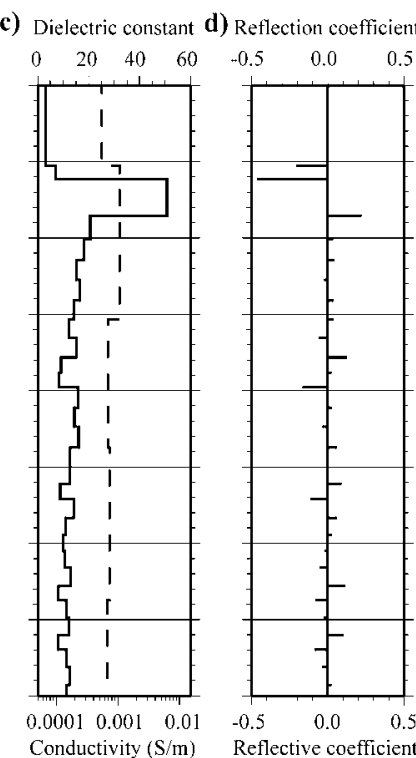

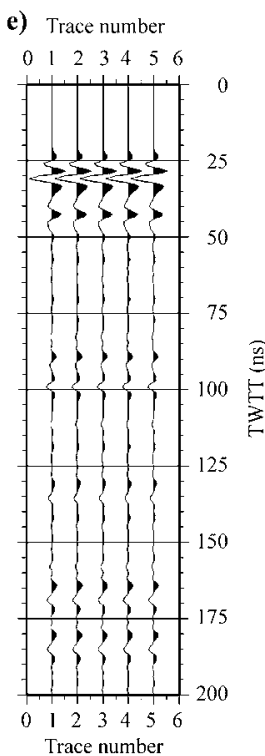

Figure 5. (a) VRP; (b) velocity (solid line) and conductivity (dashed line) models; (c) dielectric constant (solid line) and conductivity (dashed line) models; (d) reflection coefficients; and (e) synthetic radar traces for well B4. The axes are labeled as in Figure 4. a)
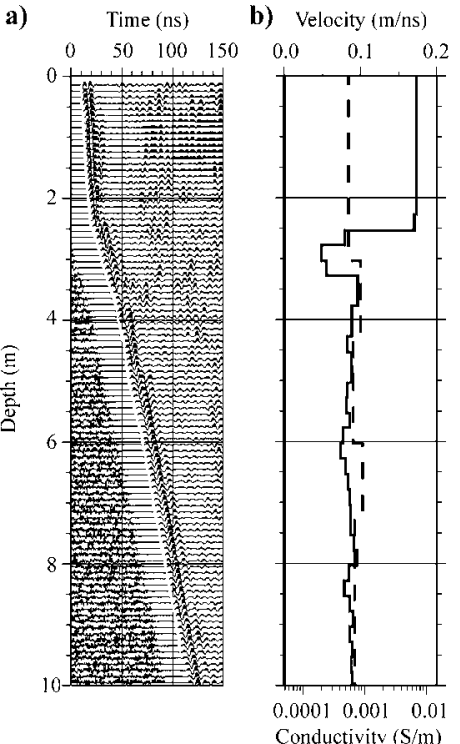

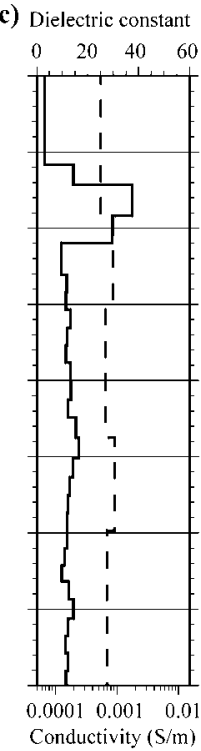

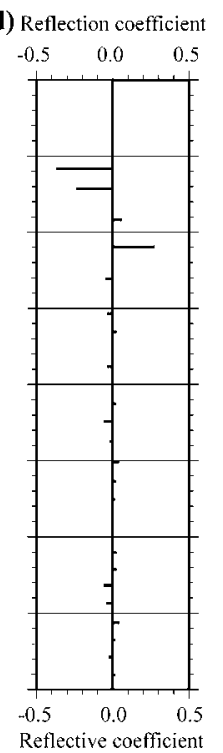

e) Trace number

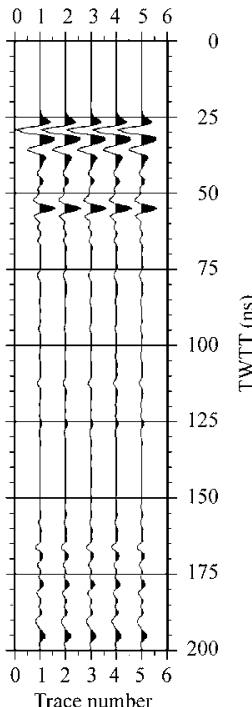

Figure 6. (a) VRP; (b) velocity (solid line) and conductivity (dashed line) models; (c) dielectric constant (solid line) and conductivity (dashed line) models; (d) reflection coefficients; and (e) synthetic radar traces for well B2. The axes are labeled as in Figure 4. 
because of the decrease in velocity in water-saturated sediments. The profiles for wells C4 (Figure 4d) and B2 (Figure 6d) have a large, positive reflection coefficient at 80 and $60 \mathrm{~ns}$, respectively, marking the base of the low-velocity (middle) layer of the threelayer radar velocity stratigraphy seen in VRPs (Figures 4a, 5a, and 6a). This low-velocity layer is present in well B4 (Figure 5b) also, but the reflection coefficient in B4 is smaller than those in $\mathrm{C} 4$ and $\mathrm{B} 2$ because the impedance contrast is not as large. The low-velocity layer in B4 has a more gradual velocity increase from top to bottom instead of the distinct boundary at the bottom that we see in the other two profiles.

For comparison with the surface GPR reflection profile, we analyzed the reflectivity with a method that uses Maxwell's equations to synthesize 1D GPR responses as a function of depth. This synthesis includes reflections and multiples (Fuchs and Mueller, 1971; Cardimona, 2003, personal communication). The method uses the reflection coefficients of a layered medium to generate synthetic data. The reflection coefficients are computed assuming plane waves that are incident on laterally homogeneous layers (Mueller, 1985).

To generate the synthetic GPR traces (Figures 4e, 5e, and 6e), we used a 150-MHz, zero-phase Ricker wavelet to approximate the source wavelet because the frequency spectrum of the observed surface-reflection data peaks near $150 \mathrm{MHz}$. Such lowering of frequency compared with the manufacturer-specified antenna frequency is common, mainly because of ground loading of the antennas.

The synthetic traces from $\mathrm{C} 4$ show a strong, complicated reflection at the water table. The model for the water table/capillary fringe used in the reflectivity modeling consists of a velocity change over two layers, which creates a complicated interference pattern. Below the water table, another reflection (arriving $\sim 10$ $-20 \mathrm{~ns}$ later than the water table reflection) returns from a small velocity decrease within the low-velocity layer.

A strong reflection from the base of the low-velocity layer occurs in wells $\mathrm{C} 4$ and $\mathrm{B} 2$. We do not see an equivalent event in the B4 reflectivity profile because the velocity changes more gradually

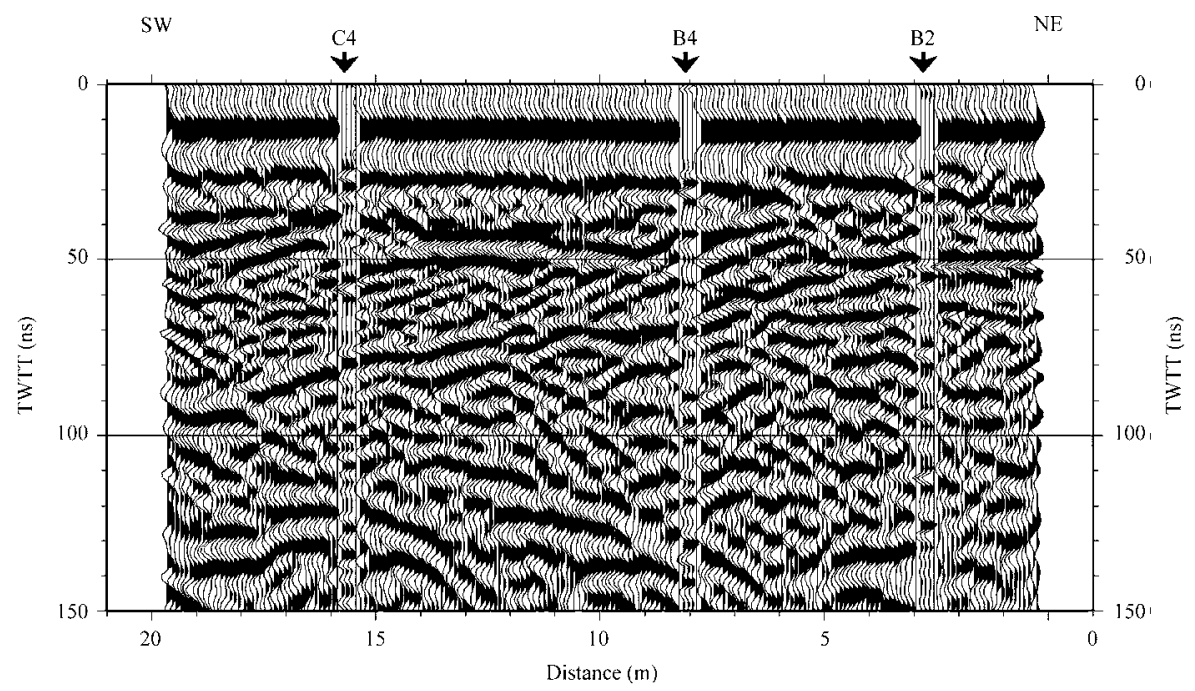

Figure 7. The migrated surface-reflection data of Figure 3 compared with the synthetic traces. Five traces have been removed and replaced by a synthetic trace repeated three times at each well location and separated from the surface data by a blank trace on each side. The labeling is the same as in Figure 3. berger, 1993). there, as noted above. This strong reflection occurs at $\sim 60 \mathrm{~ns}$ in $\mathrm{B} 2$ and at $\sim 82 \mathrm{~ns}$ in $\mathrm{C} 4$. Below this event, the synthetics consist of complicated, indistinct reflections resulting from interference between small contrasts in velocity and, possibly, multiples.

\section{Comparison of the surface-reflection profile with $1 \mathrm{D}$ models}

We compare the synthetics derived from the VRPs with the surface-reflection profile by inserting three synthetic traces at each well location (Figure 7). These traces are from the reflectivity modeling at each well and are separated from the reflection data by a blank trace on each side. We include three traces to make the synthetic reflection character more apparent. We processed the data plotted in Figure 7, including the synthetic traces, with the same parameters that were used for the data presented in Figure 3.

In general, the reflectivity synthetics from the $1 \mathrm{D}$ models fit the surface-reflection data nicely, especially for major reflections and reflection sets in the upper 50-100 ns (Figures 3b and 7). Although some of the synthetic events do not align exactly with reflections in the surface data, the synthetic traces match the strongest, most continuous reflections in the surface-reflection data: $\mathrm{B}$ (in $\mathrm{C} 4, \mathrm{~B} 4$, and $\mathrm{B} 2$ ); F (in B2); and G (in C4 and B4). Also, events in the synthetic traces at wells $\mathrm{C} 4, \mathrm{~B} 4$, and $\mathrm{B} 2$ align with some of the less prominent or less continuous reflections. These events suggest that electrical impedance discontinuities generate reflections within the units (e.g., Asprion and Aigner, 1997; Beres et al., 1999; Huggen-

The strong reflection from $\sim 95 \mathrm{~ns}$ at $19.5 \mathrm{~m}$ in the southwest to $\sim 70 \mathrm{~ns}$ at $7 \mathrm{~m}$ near well B4 ( $\mathrm{G}$ in Figure $3 \mathrm{~b}$ ) marks the base of a high-porosity, low-velocity wedge. Interestingly, the reflecting boundary for this event is only about $3.8 \mathrm{~m}$ below the ground surface. Although this high-porosity wedge appears as a dominant feature in the reflection section - about $50 \mathrm{~ns}$ TTWT at about $19 \mathrm{~m}$ - the wedge is really $1.3-\mathrm{m}$ thick beneath well C4 (Figure 2a). The high-dielectric constants associated with this layer correspond to low velocities. The low velocity of this high-porosity wedge greatly expands the time section of the relatively thin sedimentary feature.

In the vadose zone (above $\sim 25 \mathrm{~ns}$ ), the synthetics should not be compared with the surface GPR reflection data. The vadose-zone reflectivity model shows little reflection character because of the limitations of the data used to develop the model.

At $\sim 25 \mathrm{~ns}$, the synthetic water-table reflection coincides with a complicated band of reflections in the surface GPR data. The water-table reflection is more distinct in the synthetics than in the surface GPR data because the reflectivity modeling is based on a simplified, twolayer model of the water table/capillary fringe. In the subsurface, local variations in grain-size distribution would cause thickness changes in the capillary fringe or would alter the impedance contrast near the water table, thereby resulting in an indistinct water-table reflection. Figure 


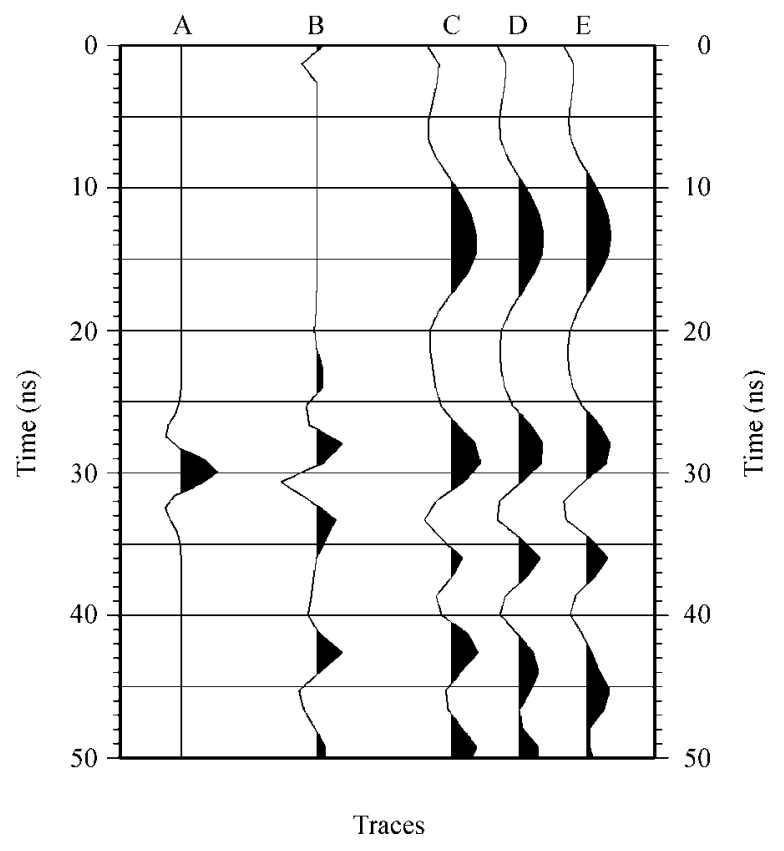

Figure 8. A synthetic trace (B) from Figure 5e and three traces $(C$, $\mathrm{D}$, and $\mathrm{E}$ ) from the reflection profile near well $\mathrm{B} 4$. Trace $\mathrm{A}$ is the zero-phase, $150-\mathrm{MHz}$ Ricker wavelet used for the synthetic trace. The water-table/capillary-fringe reflection arrives at about $30 \mathrm{~ns}$ in the plot. The energy below $38 \mathrm{~ns}$ is from beneath the water table/ capillary fringe (see Figure 5). The Ricker wavelet has been shifted to $30 \mathrm{~ns}$ to facilitate its comparison with the other traces.

8 compares the water-table reflection from a synthetic trace with the corresponding reflection data near well B4. The reflected wavelet (about $27 \mathrm{~ns}$ ) from the water table in the synthetic trace (trace B) shows a phase shift compared with the zero-phase Ricker wavelet (trace A). The synthetic wavelet is antisymmetric about an origin at $29 \mathrm{~ns}$. The negative peak is about 1.5 times as large as the earlier positive peak. The wavelets associated with the water-table reflections (traces $\mathrm{C}, \mathrm{D}$, and $\mathrm{E}$ ) are similar in waveform to those in the synthetic traces. The similarity among the synthetic wavelets and the reflection wavelets indicates that the reflecting boundary near the water table is not a simple two-layer velocity discontinuity. Instead, it is from a more complicated velocity change.

\section{SUMMARY AND CONCLUSIONS}

We used borehole data from a research field site to develop a 1D GPR reflectivity model from which to generate synthetic reflection profiles for comparison with a surface GPR reflection profile. That surface GPR reflection profile passes by the wells used in the reflectivity modeling. The signal penetrates to about $6 \mathrm{~m}(\sim 130$ $\mathrm{ns})$. The 1D reflectivity modeling incorporates velocity estimates from VRPs. For the saturated zone, we used that distribution of velocity estimates to estimate the dielectric constant distribution. We used data from borehole geophysical logs to estimate the electrical conductivity for the saturated zone. We estimated all of the electrical parameters in the unsaturated zone. We generated the synthetic reflection traces from the reflectivity models with a $150-\mathrm{MHz}$, zero-phase, Ricker wavelet source. The reflections are most sensitive to changes in dielectric constant because of the small range in electrical conductivity and the assumed uniform value for magnetic permeability for these sediments.
The synthetic traces correlate well with the surface-reflection data. Reflections from the water table/capillary fringe, the base of a sand channel (Unit 5), and the base of two relatively sand-rich lenses in a cobble-dominated unit (Unit 4) are recognizable in the surface-reflection profile and in reflectivity models in respective wells. The strong correlation between the synthetic traces and the reflection data verifies that the GPR horizon's image changes in physical properties, such as porosity changes, in the subsurface. Thus, we can use surface-reflection profiles that have been calibrated at a few well locations to widely map important hydrostratigraphic features.

\section{ACKNOWLEDGMENTS}

Inland Northwest Research Alliance grant BSU002 and the U. S. Army Research Office grant DAAH04-96-1-0318 supported this project. Cooperative arrangements with the Idaho Transportation Department, the U. S. Bureau of Reclamation, and Ada County allow development and use of the BHRS, and we gratefully acknowledge them. We acknowledge support of this research by Landmark Graphics Corporation via the Landmark University Grant Program. We thank Dr. Jonathan Mwenifumbo of the Borehole Geophysics and Petrophysics group at the Geological Survey of Canada for providing the capacitive borehole resistivity logs and Greg Oldenborger and Marc Buursink for helping collect the data. Contribution no. 0130 of the Center for Geophysical Investigation of the Shallow Subsurface at Boise State University.

\section{REFERENCES}

Arcone, S. A., D. E. Lawson, A. J. Delaney, J. C. Strasser, and J. D. Strasser, 1998, Ground-penetrating radar reflection profiling of groundwater and bedrock in an area of discontinuous permafrost: Geophysics 63, 1573-1584.

Asprion, U., and T. Aigner, 1997, Aquifer architecture analysis using ground-penetrating radar: Triassic and Quaternary examples (S. Germany): Environmental Geology, 31, 66-75.

Barrash, W., and T. Clemo, 2002, Hierarchical geostatistics and multifacies systems: Boise Hydrogeophysical Research Site, Boise, Idaho: Water Resources Research, 38, 1196, doi:10.1029/2002/WR001436.

Barrash, W., T. Clemo, and M. D. Knoll, 1999, Boise Hydrogeophysical Research Site (BHRS): Objectives, design, initial geostatistical results: Proceedings of the Symposium of Applied Geophysics and Environmental Engineering Problems, 389-398.

Barrash, W., and M. D. Knoll, 1998, Design of research wellfield for calibrating geophysical methods against hydrologic parameter: Proceedings, Conference on Hazardous Waste Research, Snowbird, Utah, May 19-21, 1998, Great Plains/Rocky Mountains Hazardous Substance Research Center, Kansas State University, 296-318.

Barrash, W., R. Morin, and D. M. Gallegos, 1997, Lithologic, hydrologic and petrophysical characterization of a coarse-grained, unconsolidated aquifer, Capital Station site, Boise, Idaho: 32nd Symposium on Engineering Geology and Geotechnical Engineering, March 26-28, Boise, Idaho, 307-323.

Barrash, W., and E. C. Reboulet, 2004, Significance of porosity for stratigraphy and textural composition in subsurface coarse fluvial deposits, Boise Hydrogeophysical Research Site: Geological Society of America Bulletin, 116, doi:10.1130/B25370.1.

Bear, J., 1972, Dynamics of fluids in porous media: Dover Publications.

Beres, M., and F. P. Haeni, 1991, Application of ground-penetrating-radar methods in hydrogeologic studies: Ground Water, 29, 375-386.

Beres, M., P. Huggenberger, A. G. Green, and H. Horstmeyer, 1999, Using two- and three-dimensional georadar methods to characterize glaciofluvial architecture: Sedimentary Geology, 129, 1-24.

Clement, W. P., M. D. Knoll, L. M. Liberty, P. R. Donaldson, P. Michaels, W. Barrash, and J. R. Pelton, 1999, Geophysical surveys across the Boise Hydrogeophysical Research Site to determine geophysical parameters of a shallow, alluvial aquifer: Proceedings of the Symposium of Applied Geophysics and Environmental Engineering Problems, 399-408.

Clement, W. P., L. M. Liberty, and W. Barrash, 2001, Using cross-hole GPR reflections to improve tomographic imaging and hydrogeologic in- 
terpretation: Geological Society of America, Abstracts with Programs, 33, A45.

Dullien, F. A. L., 1979, Porous media: Fluid transport and pore structure: Academic Press.

Fuchs, K., and G. Mueller, 1971, Computation of synthetic seismograms with the reflectivity method and comparison with observations: Geophysical Journal of the Royal Astronomical Society, 23, 417-433.

Hausrath, E. M., W. Barrash, and E. C. Reboulet, 2002, Water sampling and analysis for the Tracer/Time-Lapse Radar Imaging Test at the Boise Hydrogeophysical Research Site: Report to EPA for Grant X-970085-01-0 and to the U. S. Army Research Office for Grant AAH04-96-1-0318: Center for Geophysical Investigation of the Shallow Subsurface, Technical Report BSU CGISS 02-03, Boise State University.

Hempel, L., F. Thyssen, N. Gundestrup, H. B. Clausen, and H. Miller, 2000, A comparison of radio-echo sounding data and electrical conductivity of the GRIP ice core: Journal of Glaciology, 46, 369-374.

Holtz, R. D., and W. D. Kovacs, 1981, An introduction to geotechnical engineering: Prentice Hall.

Huggenberger, P., 1993, Radar facies: Recognition of facies patterns and heterogeneities within Pleistocene Rhine gravels, NE Switzerland, in J. L. Best, and C. S. Bristow, eds., Braided rivers: Geological Society of London, Special Publication 75, 163-176.

Hughes, C. E., 2005, Comparison of empirical relationships for hydraulic conductivity using grain size distribution, packing, and porosity information from the Boise Hydrogeophysical Research Site, Boise, Idaho: M.S. thesis, Boise State University.

Kohler, J., J. C. Moore, and E. Isaksson, 2003, Comparison of modeled and observed responses of a glacier snowpack to ground-penetrating radar: Annals of Glaciology, 37, 293-297.

Liberty, L. M., W. P. Clement, and M. D. Knoll, 1999, Surface and borehole seismic characterization of the Boise Hydrogeophysical Research Site: Proceedings of the Symposium of Applied Geophysics and Environmental Engineering Problems, 723-732.

Lizarralde, D., and S. Swift, 1999, Smooth inversion of VSP traveltime data: Geophysics, 64, 659-661.

Lohman, S. W., 1972, Ground-water hydraulics: U. S. Geological Survey, Professional Paper 708.

Mitchell, V. E., and E. H. Bennett, 1979, Geologic map of the Boise $1^{\circ}$ $\times 2^{\circ}$ quadrangle, Idaho: Idaho Bureau of Mines and Geology, scale 1: 250,000 .

Mueller, G., 1985, The reflectivity method: a tutorial: Journal of Geophysics, 58, 153-174.

Mwenifumbo, J., and M. D. Knoll, 2004, Capacitive resistivity logging to characterize hydostratigraphy: Field tests at the Boise Hydrogeophysical Research Site, Spring AGU Meeting, May 17-21, 2004, Montreal, Canada: EOS Transactions, AGU 85(17), Joint Assembly Supplement, Abstract NS41A-19.

Peretti, W. R., M. D. Knoll, W. P. Clement, and W. Barrash, 1999, 3-D GPR imaging of complex fluvial stratigraphy at the Boise Hydrogeophysical Research Site: Proceedings of the Symposium of Applied Geophysics and Environmental Engineering Problems, 555-564.

Reboulet, E. C., 2003, Quantitative analysis of unconsolidated coarse fluvial sediments from the Boise Hydrogeophysical Research Site: Statistical analysis of core and porosity data: M.S. thesis, Boise State University.

Reboulet, E. C., and W. Barrash, 2003, Core, grain-size, and porosity data from the Boise Hydrogeophysical Research Site Boise, Idaho: Center for Geophysical Investigation of the Shallow Subsurface, Technical Repor 03-02.

Szerbiak, R. B., G. A. McMechan, R. Corbeanu, C. Forster, and S. H. Snelgrove, 2001, 3-D characterization of a clastic reservoir analog: From 3-D GPR data to a 3-D fluid permeability model: Geophysics, 66, 10261037.

Tronicke, J., P. Dietrich, U. Wahlig, and E. Appel, 2002, Integrating surface georadar and crosshole radar tomography: A validation experiment in braided stream deposits: Geophysics, 67, 1495-1504.

Tronicke, J., and M. D. Knoll, 2005, Vertical radar profiling: Influence of survey geometry on first arrival traveltimes and amplitudes: Journal of Applied Geophysics, 57, 179-191.

Van Dam, R. L., and W. Schlager, 2000, Identifying causes of groundpenetrating radar reflections using time-domain reflectometry and sedimentological analyses: Sedimentology, 47, 435-499.

Van Dam, R. L., E. H. Van den Berg, M. G. Schaap, L. H. Broekema, and W. Schlager, 2003, Radar reflections from sedimentary structures in the vadose zone, in C. S. Bristow and H. M. Jol, eds., Ground penetrating radar in sediments: Applications and interpretation: Geological Society of London, Special Publication 211, 257-273. 